\title{
Infantile Pyknocytosis: End-Tidal CO, \%Micro-R Measurements, Next-Generation Sequencing, and Transfusion Avoidance with Darbepoetin
}

\author{
Timothy M. Bahr ${ }^{a} \quad$ Mari C. Knudsen ${ }^{b} \quad$ Michell Lozano-Chinga ${ }^{c}$ \\ Archana M. Agarwal ${ }^{d, e}$ Jessica A. Meznarich ${ }^{c}$ Robin K. Ohls ${ }^{a}$ \\ Robert D. Christensen ${ }^{a, c}$
}

aDivision of Neonatology, Department of Pediatrics, University of Utah, Salt Lake City, UT, USA; ${ }^{b}$ Pediatric Residency Program, University of Utah, Salt Lake City, UT, USA; ${ }^{\circ}$ Division of Hematology/Oncology, Department of Pediatrics, University of Utah, Salt Lake City, UT, USA; ${ }^{d}$ Division of Hematopathology, Department of Pathology, University of Utah, Salt Lake City, UT, USA; ${ }^{e}$ ARUP Laboratories, Salt Lake City, UT, USA

\section{What Is It about?}

In this case report, we describe a newborn with infantile pyknocytosis. We took an innovative approach to evaluation and treatment using end-tidal carbon monoxide and \%Micro-R measurements; and we avoided transfusion with weekly darbepoetin administration.

\section{Keywords}

Hemolysis · Hyperbilirubinemia $\cdot$ Darbepoetin $\cdot$ Next-generation sequencing

\begin{abstract}
Infantile pyknocytosis is a rare, self-limited, hemolytic condition of unknown pathogenesis. It is diagnosed when a neonate with Coombs-negative hemolytic anemia has abundant pyknocytes and a characteristic clinical course after other hemolytic disorders has been excluded. Previous reports suggest that transfusions might be avoidable in this condition by administering recombinant erythropoietin. We cared for a patient with this disorder where we employed novel diagnostics and therapeutics. Despite these, and a good outcome free of transfusions, we continue to consider the condition to be idiopathic.




\section{Established Facts}

- Infantile pyknocytosis, first described in 1959 , is a variety of neonatal hemolytic anemia of unclear cause. It is self-limited, remitting after 2-6 months. Erythrocyte transfusions are usually needed until remission.

- Two previous reports of this condition suggest that recombinant erythropoietin administration can diminish or prevent the need for erythrocyte transfusions.

\section{Novel Insights}

- Innovative aspects of the present report include: verifying hemolysis by elevated end-tidal CO concentration and absent haptoglobin, identifying a population of small hyperdense cells by \%Micro-R, and avoiding transfusions by weekly darbepoetin until the condition remitted at 2.5 months of age.

- All but two of 28 genes screened for a cause were normal. UGT1A1*6 was found, as was a heterozygous novel variant in PKLR (1270-15T>G), but we do not believe those explain the pathogenesis.

\section{Introduction}

The condition termed "infantile pyknocytosis" was initially described by Drs. Tuffy, Brown, and Zuelzer in 1959 [1]. They reported 11 neonates with Coombs-negative hemolytic anemia during the first few weeks after birth, and concluded that seven of them had this variety. All seven had densely stained, distorted, spiculated and contracted erythrocytes - a type of contracted burr cell (see Fig. 1) - constituting 5\% to up to 50\% of their erythrocytes. All received serial packed red blood cell transfusions, but the condition remitted spontaneously and permanently in all, generally after 2-5 months.

That initial publication and all subsequent case reports [2-21] did not reveal the cause of this condition. Though these accounts are heterogeneous, there are several unifying elements: (1) neonatal presentation with Coombs-negative jaundice and anemia, (2) blood smears show abundant contracted burr cells (pyknocytes), (3) erythrocyte transfusions are generally needed for 2 or 3 months, (4) complete remission with no residual effects.

In caring for a neonate with pyknocytosis, we performed the following novel testing and therapy, which we propose adds to the body of knowledge about this condition: (1) end-tidal CO measurements, (2) measurements of new erythrocyte parameters Micro-R and HYPO-He, (3) next-generation sequencing diagnostic testing, and (4) weekly darbepoetin to prevent erythrocyte transfusions.

\section{Methods}

CBC parameters were performed on a Sysmex analyzer (Sysmex Americas, Inc., Lincolnshire, IL). The \%Micro-R, a measure of microcytosis, is the percent of red blood cells with a $\mathrm{MCV}<60 \mathrm{fL}$ and the \%Hypo-He, a measure of erythrocyte hypochromia, is the percent of red blood cells that have a $\mathrm{MCH}<17 \mathrm{pg}[22,23]$. The hemolytic rate was assessed noninvasively by end-tidal carbon monoxide concentration (ETCO; CoSense, Capnia, Inc, Redwood City, CA, USA). After 1 week of age, ETCO values are normally <1.0 ppm [24, 25]. 


\section{Biomedicine Hub}

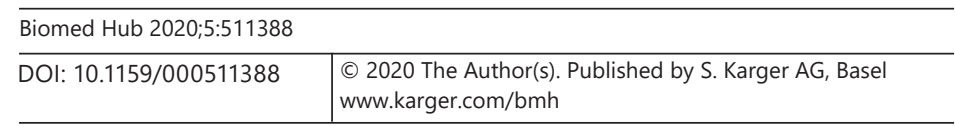

Bahr et al.: Infantile Pyknocytosis

Fig. 1. Typical pyknocytes from this patient and contracted hyperdense burr cells.

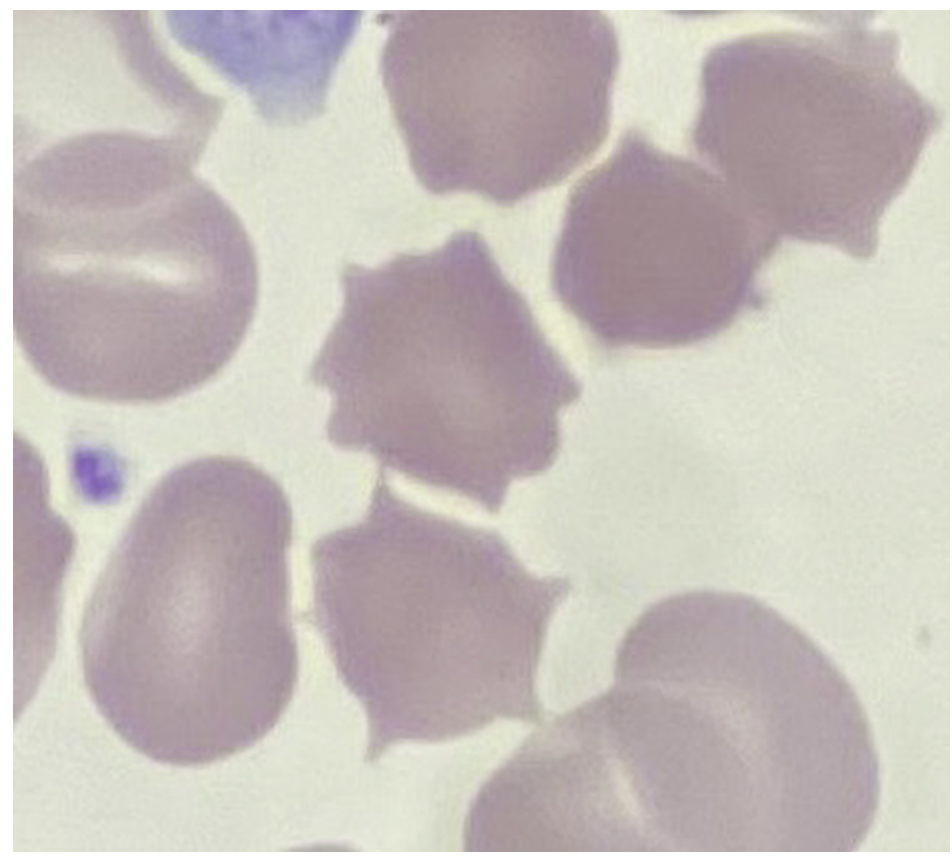

Next-generation sequencing, targeted gene capture, and library construction were performed using HaloPlex as described by the manufacturer (Agilent Technologies, Santa Clara, CA, USA) and detailed in our previous reports [26, 27]. 100-bp paired-end sequencing was done on a HiSeq 2000 system (Illumina, San Diego, CA, USA). Briefly, DNA was fragmented using restriction enzymes and denatured. A probe library was hybridized to the targeted fragments. These probes contained a method-specific sequencing motif incorporated during circularization and a barcode sequence for sample identification. Probes were biotinylated and the targeted fragments retrieved with magnetic streptavidin beads for sequencing.

Darbepoetin alfa (Aranesp, Amgen Inc, Thousand Oaks, CA, USA) was administered at a dose of $10 \mu \mathrm{g} / \mathrm{kg}$ body weight subcutaneously once weekly for 4 consecutive weeks [28].

\section{Case Report}

This female singleton was delivered vaginally at $272 / 7$ weeks gestation, with a birth weight of 1,325 g (97th percentile), length $35.5 \mathrm{~cm}$ (63rd percentile) and OFC $26 \mathrm{~cm}$ (88th percentile). Apgar scores were 6 and 7. Delayed clamping of the umbilical cord was not performed. Her mother was a healthy 20 -year-old G1P0, and was blood group A, Rh positive, antibody negative. Parents were non-consanguineous; both of Polynesian descent. The mother was treated for chlamydia trachomatis vaginalis prior to delivery, and with intrapartum antibiotics. Empiric antibiotics were begun on the neonate due to a risk of sepsis associated with prolonged rupture of membranes. She had moderate respiratory distress at birth, briefly requiring positive pressure ventilation, but was stabilized on nasal CPAP. She was weaned to room air by 1 month of age.

The baby's blood type was A (+); direct antiglobulin test negative. Two hours after birth, she was found to have a normocytic, normochromic anemia (hemoglobin $11.9 \mathrm{~g} / \mathrm{dL}$, hematocrit 33\%), with a normal RDW 13.9\%, and normal platelet $(204,000 / \mu \mathrm{L})$ and leukocyte $(17,500 / \mu \mathrm{L})$ counts.

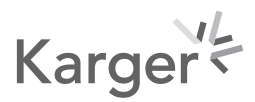



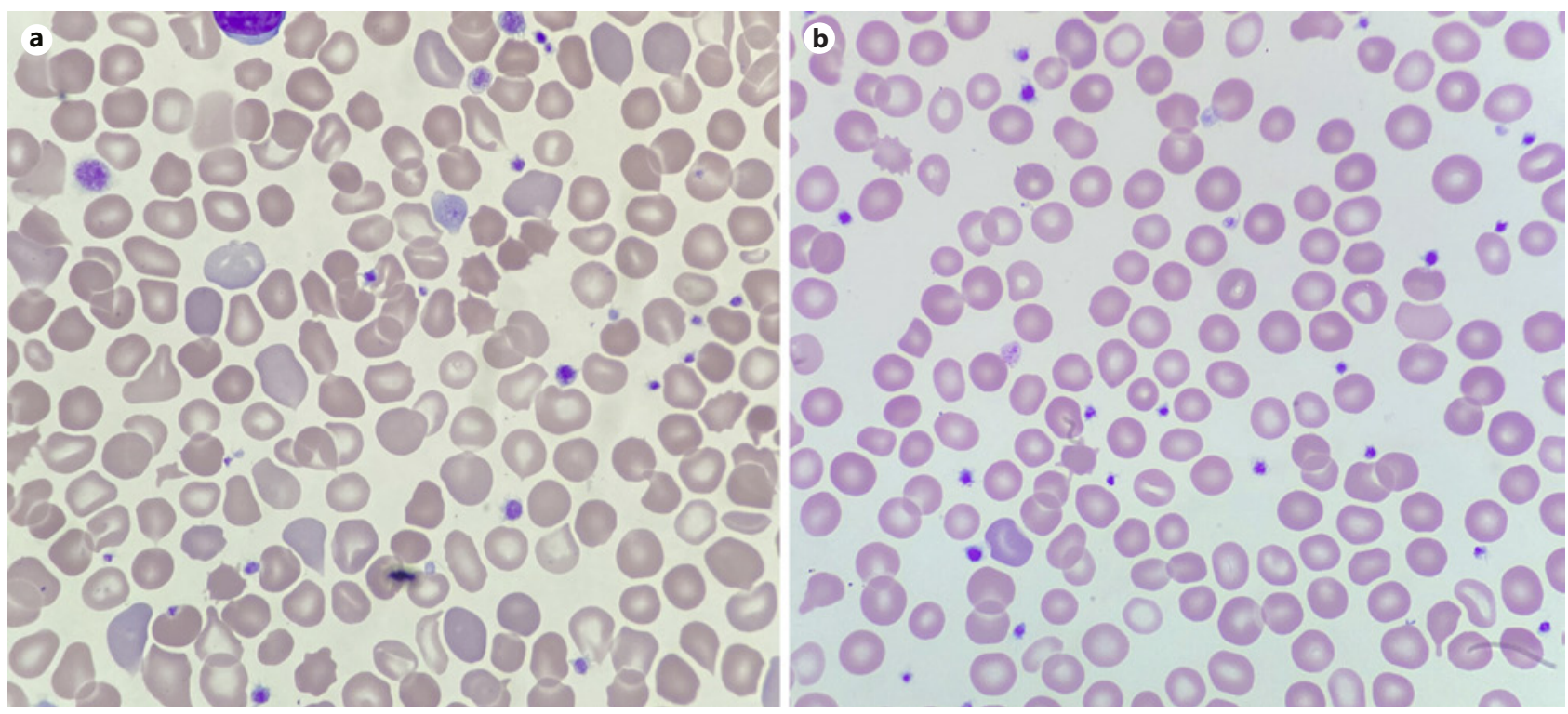

Fig. 2. a Patient's blood film at diagnosis (day of life 17), showing anisopoikilocytosis, polychromasia, abundant pyknocytes, some hyperdense contracted erythrocytes with irregular boarders but no spicules, and rare echinocytes. b Patient's blood film at outpatient follow-up after clinical resolution of hemolysis (day of life 87) showing fewer, but still present, abnormal cells.

Phototherapy was begun on day of life 2 because the total serum bilirubin was $6.8 \mathrm{mg} /$ $\mathrm{dL}$ at $37 \mathrm{~h}$. When phototherapy was stopped $24 \mathrm{~h}$ later, the serum bilirubin level rebounded rapidly; thus phototherapy was restarted. It was continued intermittently for the next 4 weeks because of repeated rebound hyperbilirubinemia.

On day of life 25, further hematological testing was done because of her continued need for phototherapy. Findings at that time included: absent serum haptoglobin $(<8 \mathrm{mg} / \mathrm{dL}$; below the lower limit of detection), and elevated end-tidal CO (2.3 ppm; normal $<1.0 \mathrm{ppm})$, which were diagnostic of hemolysis. Micro-R (7.3\%) and Hypo-HE (16.8\%) were both elevated, indicating a microcytic, hypochromic process. Her newborn screen was negative for hemoglobinopathy both on days of life 2 and 9 (by isoelectric focusing). The blood smear was consistent with a diagnosis of infantile pyknocytosis (Fig. 2a). Specific findings included marked anisopoikilocytosis, $>25 \%$ pyknocytes, polychromasia, and occasional echinocytes and microspherocytes.

With a diagnosis of infantile pyknocytosis, pending evaluation with our 28-gene nextgeneration sequencing panel $[26,27]$, she was treated with darbepoetin $(10 \mu \mathrm{g} / \mathrm{k}$ subcutaneously once weekly for 4 consecutive weeks) and iron supplementation (4-6 mg/kg/day enterally).

The hereditary hemolytic anemia sequencing panel identified no variants among 26 of the 28 genes tested. One mildly pathogenic variant was found in the UGT1A1 (UDP-glucuronosyltransferase) gene and one variant of uncertain significance was identified in the PKLR (pyruvate kinase) gene. The heterozygous UGT1A1 variant is known as *6 and is an intronic single base pair change (c. $211 \mathrm{G}>\mathrm{A})$. It results in a mild decrease in bilirubin glucuronidation (and subsequent elimination).

The variant of uncertain significance in the PKLR gene has not previously been reported. It consists of the nucleic acid change c.1270-15T $>$ G. This mutation is absent from general population databases (Exome Variant Server, Genome Aggregation Database). Computa- 
tional analysis (Alamut v1.11) predicts it to impact splicing by weakening the nearby canonical acceptor splice site. Pyruvate kinase enzyme level, obtained once her PKLR mutation was identified, was $11.0 \mathrm{U} / \mathrm{g}$ hgb (normal 4.6-11.2).

She was discharged from the hospital on day of life 76 in room air, on oral and gavage feedings, with a hematocrit of 33.5\%, hemoglobin $10.8 \mathrm{~g} / \mathrm{dL}, \mathrm{MCV} 87.2 \mathrm{fL}, \mathrm{RDW} 20.2 \%$, Micro-R 8.7\%, reticulocyte count 2.7\%, end-tidal CO $<1.0 \mathrm{ppm}$, and bilirubin $2.1 \mathrm{mg} / \mathrm{dL}$. Her peripheral smear contained far fewer pyknocytes. It had been 3 weeks since her last darbepoetin dosing. Though she was mildly iron deficient on day of life 20 (reticulocyte hemoglobin $27.7 \mathrm{pg}$ ), she remained on enteral iron supplementation through the hospitalization and achieved iron sufficiency by the time of discharge (reticulocyte hemoglobin $32.2 \mathrm{pg}$ ). She did not receive a red blood cell transfusion during her 76-day hospitalization.

At outpatient follow-up on day of life 87, she was well and no longer requiring use of a gavage tube for enteral nutrition. Her hematocrit was $31.7 \%$, hemoglobin $10.8 \mathrm{~g} / \mathrm{dL}$, MCV 84.8 fL, Micro-R 10.7\%, reticulocyte count 2.0\%. Her reticulocyte hemoglobin was $34.4 \mathrm{pg}$, suggesting that her iron stores were adequate. Peripheral smear was essentially normal with only rare pyknocytes and resolution of polychromasia (see online suppl. Table; for all online suppl. material, see www.karger.com/doi/10.1159/000511388; for all laboratory values).

\section{Discussion/Conclusion}

Since 1959, patients with infantile pyknocytosis have been reported from the USA [1, 4, 20], France [2, 8, 15, 16, 18, 21], Greece [3], Mexico [5], Australia [6], Lebanon [7, 9], Italy [10, 14, 17], Belgium [11], Israel [12], Brazil [13], and the United Kingdom [19]. Similarities in the reported cases are striking; all have pyknocytes on the blood film, all have anemia and jaundice that resolves after 2-6 months, and practically all received multiple red blood cell transfusions. To date, no genetic mutations have been identified as causative, thus the pathogenesis remains obscure.

Despite the similarities, differences between reported patients are also striking. Stephan et al. [18] and Bobée and Lahary [21], reported cases where Heinz bodies were numerous, suggesting involvement of oxidative stress in the pathogenesis. In contrast, Tuffy et al. [1] did not find Heinz bodies in any of their seven cases. Most do not have their hemolytic jaundice and anemia recognized until at least 1 week or 2 after birth. However, Maxwell et al. [6] found evidence of intrauterine hemolysis in two cases.

Moreover, erythrocytes that are called pyknocytes seem to differ somewhat between the various reports. All publications that include blood films illustrate anisopoikilocytosis with many hyperdense and irregular shaped erythrocytes but some such cells clearly have spicules, like burr cells, while others have spicules that appear contracted and shriveled (pyknocytes, see Fig. 1), and still others have small hyperdense erythrocytes with irregular borders but no spicules. The percentage of cells called pyknocytes range, in various reports, from about $10 \%$ of erythrocytes to $>20 \%$. In our patient, the small size of the pyknocytes is quantified clearly by the markedly elevated percent Micro-R [23]. It is not clear whether the differences in Heinz bodies, age at diagnosis, or cell shapes, represent different stages of the disorder, or different underlying pathogenic causes. Lacking better information, it seems likely that pyknocytosis may be a feature of several different varieties of Coombs-negative neonatal hemolytic disorders.

It is curious that most neonates have an occasional pyknocyte found on their blood film. However, pyknocytes are not normally seen in the blood of healthy children or adults [1]. On that basis, perhaps this syndrome is the accentuation of a normal birth-associated physiological process. Two other clues to pathogenesis are: first, the condition invariably remits and

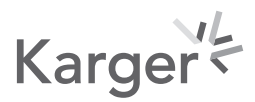


does not recur, and second the problem is not intrinsic to erythrocytes but is in the environment of the erythrocytes. Specifically, Keimowitz and Desforges found that $\mathrm{Cr}$ labeled donor red cells transfused into these patients became pyknocytes [4]. Tuffy et al. [1] and Ackerman [5] reported neonates with pyknocytosis who received exchange transfusion and the donor cells became pyknocytes.

The kinetic cause of this variety of anemia is thought to be hemolytic, on the basis of hyperbilirubinemia and reticulocytosis. Our findings of an elevated end-tidal $\mathrm{CO}$ and absent haptoglobin are supportive of a hemolytic pathogenesis [24, 25].

The mainstay of treating neonates with this condition is erythrocyte transfusion. However, Amendola et al. [10], Buzzi et al. [14] (of the same group), and Bago et al. [16] tried a different approach. They administered recombinant erythropoietin and found that, thereafter, transfusions were not needed. It is peculiar that a hemolytic disorder would be treatable with a stimulator of erythroid production, since these patients have a high reticulocyte count. Reported reticulocyte counts tend to be in the 4-8\% range. We used a novel strategy with weekly darbepoetin administration, which kept the reticulocyte $>10 \%$ and maintained a normal hemoglobin level, thus averting transfusions.

We utilized a next-generation sequencing panel examining 28 genes known to be involved in neonatal hemolytic decoders. We found the results to be interesting but not definitive. No variants were identified in 26 of the 28 genes sequenced. We did identify the UGT1A1*6 variant, c. $211 \mathrm{G}>\mathrm{A}$. This is a mildly pathogenic variant, associated with diminished UGT1A1 enzyme levels. It is found predominantly in the East Asian population. Sato et al. [29] reported that the $* 6$ variant becomes a risk factor for neonatal jaundice when feedings are inadequate. Perhaps the $* 6$ variant is a partial explanation for her prolonged jaundice but does not explain her hemolysis or distorted erythrocyte shapes.

We also identified a heterogenous novel mutation in the gene encoding pyruvate kinase. In silico analysis predicts this to be a damaging mutation, likely producing severe pyruvate kinase deficiency (OMIM 266,200) if coinherited with another PKLR damaging mutation. However, since her pyruvate kinase enzyme level was normal, we maintain that this mutation did not contribute to her hemolytic condition.

In conclusion, we cared for a patient with infantile pyknocytosis where the following were clarified: (1) the anemia was definitely hemolytic, by elevated ETCO and absent haptoglobin, (2) a population of dense microcytes was quantified by an elevated \%Micro-R, (3) finding the $U G T 1 A 1 * 6$ variant might be a partial explanation for her prolonged jaundice, (4) her PKLR mutation is not sufficient to explain the phenotype, (5) treatment with darbepoetin was associated with transfusion avoidance. Thus, some progress has been made, but we still consider infantile pyknocytosis to be an idiopathic and likely heterogeneous condition.

\section{Statement of Ethics}

The subject's mother gave informed consent to publish this deidentified case.

\section{Conflict of Interest Statement}

The authors have no conflicts of interest to declare.

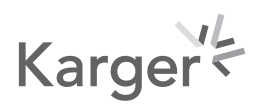




\section{Funding Sources}

No funding was received relative to this case or this report.

\section{Author Contributions}

Drs. Bahr and Christensen conceptualized and designed the commentary, drafted the initial manuscript, revised the manuscript, and approved of the final manuscript and agreed to be accountable for all aspects of the work. Drs. Knudsen, Lozano-Chinga, Agarwal, Meznarich and Ohls critically reviewed and revised the manuscript and approved the final manuscript as submitted, and agreed to be accountable for all aspects of the work.

\section{References}

1 Tuffy P, Brown AK, Zuelzer WW. Infantile pyknocytosis; a common erythrocyte abnormality of the first trimester. AMA J Dis Child. 1959 Aug;98(2):227-41.

2 Lovric VA. Infantile pyknocytosis occurring in dissimilar twins. Med J Aust. 1960 Oct;47(2):579-80.

3 Zannos-Mariolea L, Kattamis C, Paidoucis M. Infantile pyknocytosis and glucose-6-phosphate dehydrogenase deficiency. Br J Haematol. 1962 Jul;8(3):258-65.

4 Keimowitz R, Desforges JF. Infantile pyknocytosis. N Engl J Med. 1965 Nov;273(21):1152-4.

5 Ackerman BD. Infantile pyknocytosis in Mexican-American infants. Am J Dis Child. 1969 Apr;117(4):417-23.

6 Maxwell DJ, Seshadri R, Rumpf DJ, Miller JM. Infantile pyknocytosis: a cause of intrauterine haemolysis in 2 siblings. Aust N Z J Obstet Gynaecol. 1983 Aug;23(3):182-5.

7 Dabbous IA, El Bahlawan L. Infantile pyknocytosis: a forgotten or a dead diagnosis? J Pediatr Hematol Oncol. 2002 Aug-Sep;24(6):507.

8 Eyssette-Guerreau S, Bader-Meunier B, Garcon L, Guitton C, Cynober T. Infantile pyknocytosis: a cause of haemolytic anaemia of the newborn. Br J Haematol. 2006 May;133(4):439-42.

9 Dahoui HA, Abboud MR, Saab R, Farra C, Sinno D, Dabbous I, et al. Familial infantile pyknocytosis in association with pulmonary hypertension. Pediatr Blood Cancer. 2008 Aug;51(2):290-2.

10 Amendola G, Di Concilio R, D’Urzo G, Danise P, Parisi G, della Ragione F, et al. Erythropoietin treatment can prevent blood transfusion in infantile pyknocytosis. Br J Haematol. 2008 Nov;143(4):593-5.

11 Limme B, Dresse MF, Ketelslegers O, Rigo V, Hoyoux C. [Infantile pyknocytosis: a rare form of neonatal hemolytic anemia. 5 case-studies]. Arch Pediatr. 2008 Dec;15(12):1765-8. French.

12 Kraus D, Yacobovich J, Hoffer V, Scheuerman 0, Tamary H, Garty BZ. Infantile pyknocytosis: a rare form of neonatal anemia. Isr Med Assoc J. 2010 Mar;12(3):188-9.

13 Coutinho M, Costa E, Monteiro T, Silva G, Costa H, Guedes A, et al. Infantile pyknocytosis: an under-recognized form of neonatal hemolytic anemia? Lab Hematol. 2012 Dec;18(4):27-9.

14 Buzzi E, Scognamillo R, Girardi E, Amendola G, Dall'Agnola A. Infantile pyknocytosis: effectiveness of erythropoietin treatment. J Ped Neo Indiv Med. 2013;2:81-4.

15 El Nabouch M, Rakotoharinandrasana I, Ndayikeza A, Picard V, Kayemba-Kay's S. Infantile pyknocytosis, a rare cause of hemolytic anemia in newborns: report of two cases in twin girls and literature overview. Clin Case Rep. 2015 Jul;3(7):535-8.

16 Bagou M, Rolland E, Gay C, Patural H. [Infantile pyknocytosis: A cause of noenatal hemolytic anemia. Is recombinant erythropoietin an alternative to transfusion?]. Arch Pediatr. 2016 Jan;23(1):56-60. French.

17 Berardi A, Balestri E, Bonacorsi G, Chiossi C, Palazzi G, Spaggiari E, et al. Neonatal pyknocytosis in a preterm dizygotic twin. World J Clin Pediatr. 2017 Nov;6(4):176-9.

18 Stephan C, Phulpin A, Steschenko D, Lesesve JF, Perrin J. Oxidative stress-related infantile pyknocytosis with Heinz bodies. Transfusion. 2018 Apr;58(4):840-1.

19 Rees C, Lund K, Bain BJ. Infantile pyknocytosis. Am J Hematol. 2019 Apr;94(4):489-90.

20 Castillo J, Ness TE, Mehta PS. Infantile Pyknocytosis: an uncommon cause of newborn hemolytic anemia. Pediatr Hematol Oncol. 2020 May;42(4):e251-e253. https://doi.org/10.1097/MPH.0000000000001461.

21 Bobée V, Lahary A. Numerous Heinz bodies in a case of infantile pyknocytosis. Blood. 2020 Feb;135(9):701.

22 Urrechaga E, Borque L, Escanero JF. Potential utility of the new Sysmex XE 5000 red blood cell extended parameters in the study of disorders of iron metabolism. Clin Chem Lab Med. 2009;47(11):1411-6.

23 Buttarello M, Pajola R, Novello E, Mezzapelle G, Plebani M. Evaluation of the hypochromic erythrocyte and reticulocyte hemoglobin content provided by the Sysmex XE-5000 analyzer in diagnosis of iron deficiency erythropoiesis. Clin Chem Lab Med. 2016 Dec;54(12):1939-45. 
24 Christensen RD, Malleske DT, Lambert DK, Baer VL, Prchal JT, Denson LE, et al. Measuring End-Tidal Carbon Monoxide of Jaundiced Neonates in the Birth Hospital to Identify Those with Hemolysis. Neonatology. 2016; 109(1):1-5.

25 Christensen RD, Lambert DK, Henry E, Yaish HM, Prchal JT. End-tidal carbon monoxide as an indicator of the hemolytic rate. Blood Cells Mol Dis. 2015 Mar;54(3):292-6.

26 Rets A, Clayton AL, Christensen RD, Agarwal AM. Molecular diagnostic update in hereditary hemolytic anemia and neonatal hyperbilirubinemia. Int J Lab Hematol. 2019 May;41(S1 Suppl 1):95-101.

27 Agarwal AM, Nussenzveig RH, Reading NS, Patel JL, Sangle N, Salama ME, et al. Clinical utility of next-generation sequencing in the diagnosis of hereditary haemolytic anaemias. Br J Haematol. 2016 Sep;174(5):806-14.

28 Patel S, Ohls RK. Darbepoetin administration in term and preterm neonates. Clin Perinatol. 2015 Sep;42(3): 557-66.

29 Sato H, Uchida T, Toyota K, Kanno M, Hashimoto T, Watanabe M, et al. Association of breast-fed neonatal hyperbilirubinemia with UGT1A1 polymorphisms: 211G[\{GT\}]A (G71R) mutation becomes a risk factor under inadequate feeding. J Hum Genet. 2013 Jan;58(1):7-10. 